\title{
PENGARUH JENIS KONDUKTOR DAN PEMBERSIHAN ELEKTROLISIS TERHADAP KUALITAS WARNA DAN KONDUKTIFITAS PERMUKAAN ALUMINIUM
}

1) Jurusan Teknik Mesin, Politeknik Negeri Malang Jl. Soekarno Hatta No. 09, Jatimulyo, Kec.

Lowokwaru, Kota Malang, Jawa Timur 65141

Corresponding email*: haris.puspito@polinema.ac.id

Received: 26-08-2020 Accepted: 15-12-2020 Published:28-12-2020

(C)2020 Politala Press. All Rights Reserved.

\section{Utsman Syah Amrullah ${ }^{1)}$, Mochamad Muzaki ${ }^{1)}$, Elfin Lailatun Nur'aini ${ }^{1)}$, dan Haris Puspito Buwono ${ }^{1 *)}$}

Abstrak. Peningkatkan aspek dekoratif pada permukaan aluminium dapat dilakukan melalui proses finishing seperti pewarnaan melalui pewarnaan anodisasi. Proses pewarnaan anodisasi meliputi pembersihan, pembentukan pori-pori, pewarnaan, dan penutupan pori-pori aluminium oksida. Proses pembersihan dapat dilakukan secara mekanik dan kimiawi. Salah satu cara pada pembersihan kimiawi adalah penggunaan proses elektrolisis. Penelitian, ini berupaya untuk mengetahui pengaruh pembersihan secara elektrolisis sebelum proses anodisasi atau disebut sebagai anodisasi multi-langkah. Proses pembersihan elektrolisis dan anodisasi dilakukan dalam larutan $15 \%$ asam sulfat. Adapun pewarna yang digunakan adalah pewarna tinta printer (merk Exxx) warna biru yang banyak ditemukan di pasaran. Hasil penelitian menunjukkan bahwa aluminium yang dibersihkan melalui elektrolisis tersebut dapat diwarnai. Kualitas warna kemudian dibandingkan dengan proses pembersihan tanpa elektrolisis. Pada penelitian ini juga menggunakan kawat konduktor tembaga dan aluminium. Sifat konduktifitas aluminium hasil anodisasi sangat dipengaruhi oleh jenis konduktor yang digunakan tersebut. Kata Kunci: Anodisasi, Dua tahap, Elektrolisis, Pewarnaan, Konduktifitas.

\begin{abstract}
Improving the decorative value of the aluminum surface was performed by anodized coloring. The anodized coloring process involves cleaning, pores forming, coloring, and sealing. One of the essential steps in the anodized coloring is surface preparation via cleaning of the aluminum surface. This research conducts electrolytic cleaning to observe the effect of cleaning on the pore formation and the color distribution. The electrolytic cleaning and anodizing processes were carried out in a $15 \%$ sulfuric acid solution. The blue color dye is the commercial printer ink. The results showed that the anodized aluminum processed and unprocessed by electrolytic cleaning could be colored using industrial printer ink. The effect of the cleaning process and conductors type was studied toward color distribution quality. The results show that the electrolytic cleaning process for 15 minutes improves color distribution quality, and the conductors type affected conductivity of the anodized aluminum surface. Probably the electrolytic cleaning changed the formation of the pores. Keywords: Anodizing, Coloring, Conductivity, Electrolytic Cleaning, and TwoStep Anodization.
\end{abstract}

\section{Pendahuluan}

Proses anodisasi itu tercatat digunakan oleh industri pada tahun 1923 [1]. Proses ini berupaya untuk mempertebal lapisan aluminium oksida pada permukaannya. Pembentukan lapisan oksida tersebut mampu menjadi lapisan pelindung. Proses pewarnaan aluminium melalui anodisasi didasarkan pada prinsip pembentukan pori-pori pada permukaan aluminium. Pembentukan pori-pori tersebut dilaksanakan secara anodisasi yang juga merupakan proses elektrolisis. Aluminium diberikan muatan positif dan berperan sebagai anoda pada catu daya 
searah $(D C)$, dan sebagai kutub negatif dapat digunakan konduktor seperti aluminium, baja atau jenis lainnya. Pada anoda terjadi reaksi oksidasi yang melepaskan ion aluminium ke dalam larutan. Akibat pelepasan ion tersebut, terbentuk rongga-rongga atau pori-pori pada permukaan aluminium. Pori-pori yang terbentuk itu diisi pewarna dan dilanjutkan sealing [2].

Proses anodisasi merupakan proses korosi yang terkendali. Proses ini dipengaruhi oleh jenis pembersihan, rapat arus, waktu, media elektrolit, pengadukan, temperatur, pengotor dan aerasi udara [3]-[9]. Proses pembersihan aluminium dapat dibagi menjadi dua kategori besar yaitu pembersihan secara mekanik dan kimiawi. Pembersihan secara kimiawi lebih disukai karena mampu menangani dimensi dan tingkat kekotoran aluminium yang bervariasi dengan hasil yang memuaskan. Proses anodisasi satu tahap menggunakan pewarna tinta printer warna biru terbukti mampu digunakan sebagai pewarna [10].

Proses pembersihan merupakan salah satu faktor yang menentukan dalam pembentukan pori-pori [11][13]. Beberapa hasil yang dilaporkan mengindikasikan bahwa penggunaan anodisasi dua tahap dapat menghasilkan pori-pori berukuran nano yang tersusun secara terstruktur [11], jenis aluminium oksida adalah hidrofilik [14], dan pada logam lain seperti $\mathrm{TiO}_{2}$ pori-pori dapat membentuk struktur yang lebih baik [12] dibandingkan anodisasi satu tahap. Namun, aplikasi anodisasi 2 tahap pada pewarnaan hingga saat ini belum dieksplorasi secara luas. Untuk itu, perlu dilakukan penelitian aplikasi anodisasi 2 tahap untuk proses pewarnaan.

Pada penelitian ini digunakan metode pembersihan secara kimiawi dan dipelajari pengaruh pembersihan elektrolitik terhadap kualitas warna aluminium oksida. Proses pembersihan secara elektrolitik tersebut dilakukan dengan cara proses anodisasi. Pada penelitian ini proses anodisasi aluminium sebanyak dua kali maka proses disebut sebagai anodisasi dua tahap. Proses pembanding adalah anodisasi sebanyak satu kali atau anodisasi satu tahap. Selain itu juga dipelajari pengaruh penggunaan konduktor terhadap konduktifitas aluminium oksida.

\section{Metodologi}

Proses anodisasi didasarkan pada proses yang dikembangkan oleh peneliti sebelumnya yang terdiri dari empat bagian yaitu pembersihan permukaan aluminium, anodisasi, pewarnaan, dan sealing [10]. Benda kerja proses anodisasi menggunakan aluminium tipe AA1100 yang mempunyai dimensi (p x 1 x t) $81 \mathrm{~mm} \times 22 \mathrm{~mm} \times 3$ mm sebagaimana disajikan pada Gambar 1. Proses penyiapan aluminium dimulai dari pemotongan, pemberian tanda atau kode dengan cara stamping untuk mempermudah identifikasi, pembuatan lubang pengait kawat konduktor dengan cara pengeboran menggunakan mesin bor tangan. Kemudian benda kerja dibersihkan melalui tujuh tahap pembersihan secara kimiawi. Zat-zat pembersih mempunyai grade teknis yang digunakan tanpa perlakuan pemurnian tambahan. Secara berurutan, tahap pembersihan adalah pembersihan menggunakan sabun, larutan $10 \% \mathrm{NaOH}$ (natrium hidroksida), $10 \% \mathrm{HCl}$ (asam klorida), dan campuran larutan $5 \% \mathrm{HNO}_{3}$ (asam nitrat) dan $80 \% \mathrm{H}_{3} \mathrm{PO}_{4}$ (asam fosfat). Durasi waktu setiap proses pembersihan adalah 3 menit, kecuali pada pembersihan terakhir dengan durasi 15 menit. Setiap selesai satu tahap pembersihan, benda kerja dibilas menggunakan air bersih (aquades).

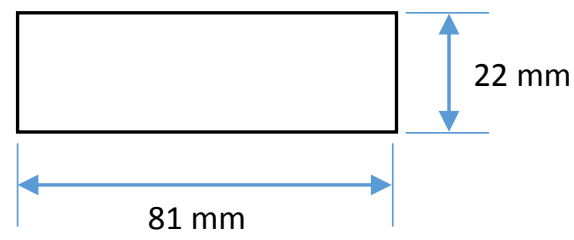

Gambar 1. Ukuran benda kerja berupa aluminium

Setelah proses pembersihan, tahap selanjutnya adalah proses anodisasi. Pada proses anodisasi, hanya sebagian benda kerja yang dianodisasi atau yang dicelupkan ke dalam larutan asam sulfat. Ukuran benda kerja adalah $81 \mathrm{~mm}$ x $22 \mathrm{~mm}$ × $3 \mathrm{~mm}$ dengan bagian tercelup dalam larutan adalah $61 \mathrm{~mm}$ × $22 \mathrm{~mm}$ × $3 \mathrm{~mm}$. Proses Anodisasi dilakukan untuk menghasilkan pori-pori pada permukaan aluminium. Proses ini dilaksanakan dengan cara memasukkan benda kerja ke dalam larutan $15 \% \mathrm{H}_{2} \mathrm{SO}_{4}$ (asam sulfat) pada arus dan waktu yang sesuai dengan variabel yang telah ditentukan. Perbandingan katoda terhadap anoda adalah 1:1 dan jarak antar keduanya adalah 8 $\mathrm{cm}$. Proses anodisasi dilangsungkan pada temperatur kamar $\left(27^{\circ} \mathrm{C}\right)$ tanpa pengadukan dan aerasi. Pada anodisasi dua tahap, setelah proses anodisasi pertama, aluminium di bersihkan kembali dengan $10 \% \mathrm{HCl}$ dan selanjutnya di-anodisasi kembali.

Variabel yang digunakan pada proses anodisasi ini terdiri dari rapat arus, waktu, jumlah tahap anodisasi dan jenis konduktor. Secara keseluruhan variabel tersebut disajikan pada Tabel 1.

Setelah proses anodisasi, benda kerja dibersihkan menggunakan air bersih kemudian dilakukan tahap pewarnaan aluminium dengan menggunakan larutan pewarna biru yang berasal dari tinta printer yang tersedia secara komersial pada temperatur $50^{\circ} \mathrm{C}$ dengan durasi 5 menit. Selanjutnya benda kerja dibilas menggunakan air 
bersih (aquades) dan proses selanjutnya adalah sealing untuk penutupan pori-pori dengan cara benda kerja dimasukkan ke dalam air panas.

Identifikasi warna standar RGB dan HEX dilakukan menggunakan software color identifier yang tersedia secara gratis melalui yang diakses melalui laman colorcodepicker.com dengan menggunakan jenis warna yang paling dominan. Pengujian konduktifitas permukaan aluminium hasil anodisasi yang menggunakan konduktor alumium dan tembaga dilaksanakan menggunakan pembacaan ohm-meter.

Tabel 1. Identitas benda kerja dan parameter.

\begin{tabular}{|cccc|}
\hline Kode Benda* & $\begin{array}{c}\text { Rapat Arus } \\
\left(\mathbf{A} / \mathbf{c m}^{2}\right)\end{array}$ & $\begin{array}{c}\text { Waktu } \\
(\text { menit)** }\end{array}$ & $\begin{array}{c}\text { Jumlah } \\
\text { Tahap }\end{array}$ \\
\hline 1A1001 & 0.01 & 45 & 1 \\
\hline 2T1001 & 0.01 & 45 & 1 \\
\hline $3 \mathrm{~A} 1001$ & 0.01 & 90 & 1 \\
\hline 4T1001 & 0.01 & 90 & 1 \\
\hline 5A2001 & 0.01 & $15+75$ & 2 \\
\hline 6T2001 & 0.01 & $15+75$ & 2 \\
\hline 7A2002 & 0.02 & $15+45$ & 2 \\
\hline 8T2002 & 0.02 & $15+45$ & 2 \\
\hline
\end{tabular}

*Penamaan benda kerja didasarkan pada:

a) huruf pertama menyatakan nomer benda kerja,

b) huruf kedua menyatakan jenis konduktor yaitu A untuk aluminium dan T untuk tembaga,

c) huruf ketiga menyatakan jumlah tahap yaitu 1 untuk 1 tahap dan 2 untuk 2 tahap, dan

d) tiga huruf terakhir menyatakan rapat arus yaitu 001 menyatakan rapat arus $0,01 \mathrm{~A} / \mathrm{cm}^{2}$ dan 002 menyatakan rapat arus $0,02 \mathrm{~A} / \mathrm{cm}^{2}$. **Waktu anodisasi menyatakan:

a) satu tahap anodisasi adalah 45 atau 90 menit

b) dua tahap anodisasi adalah $15+75=90$ menit dan $15+45=60$ menit. Lima belas menit pertama menunjukkan anodisasi tahap pertama.

\section{Hasil dan Pembahasan}

Pembersihan permukaan aluminium secara anodisasi telah dilakukan secara anodisasi. Langkah awalC penelitian ini dilaksanakan dengan cara melakukan validasi anodisasi satu tahap yang dilaksanakan pada rapat arus $0,01 \mathrm{~A} / \mathrm{cm}^{2}$, dalam larutan $15 \%$ asam sulfat seperti yang disajikan pada Gambar 2. Gambar 2 memperlihatkan aluminium yang telah diproses anodisasi dengan perlakuan sebelum dan sesudah pewarnaan. Sebelum pewarnaan benda kerja mempunyai warna putih cenderung kusam seperti warna logam aluminium pada umumnya dan setelah pewarnaan warna aluminium berubah menjadi biru sebagaimana warna tinta printer yang digunakan. Identitas warna pada permukaan aluminium sebelum dan setelah proses pewarnaan dalam proses anodisasi berdasarkan standar RGB dan HEX disajikan pada Tabel 2.
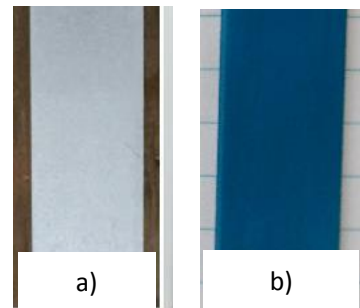

Gambar 2. Permukaan aluminium setelah proses anodisasi 1 tahap dalam larutan $15 \% \mathrm{H}_{2} \mathrm{SO}_{4}$, rapat arus $0.01 \mathrm{~A} / \mathrm{cm}^{2}$ selama 90 menit a) sebelum pewarnaan, dan b) setelah pewarnaan.

Proses pewarnaan menggunakan tinta printer pada penelitian ini menghasilkan warna permukaan yang baik, sebagaimana upaya sebelumnya pada penggunaan tinta printer yang tersedia secara komersial sebagai pewarna permukaan aluminium hasil anodisasi juga telah menghasilkan kualitas warna yang baik [10]. Berdasarkan kondisi tersebut, proses pewarnaan pada permukaan aluminium ini telah berhasil dilaksanakan. 
Tabel 2. Identitas warna lapisan oksida aluminium berdasarkan RGB dan HEX setelah proses anodisasi dalam larutan $15 \% \mathrm{H}_{2} \mathrm{SO}_{4}$, dan rapat arus $0.01 \mathrm{~A} / \mathrm{cm}^{2}$ sebelum dan sesudah pewarnaan selama 90 menit.

\begin{tabular}{|ccccc|}
\hline \multirow{2}{*}{$\begin{array}{c}\text { Waktu } \\
\text { (menit) }\end{array}$} & \multicolumn{2}{c}{ RGB } & \multicolumn{2}{c|}{ HEX } \\
\cline { 2 - 5 } & Sebelum & Sesudah & Sebelum & Sesudah \\
\hline 90 & $83,70,58$ & $4,65,105$ & $\# 53463 a$ & $\# 044169$ \\
\hline
\end{tabular}

\section{Pengaruh Konduktor terhadap Kualitas Warna}

Gambar 3 memperlihatkan benda kerja yang telah diproses anodisasi 1 (satu) tahap dalam larutan $15 \%$ $\mathrm{H}_{2} \mathrm{SO}_{4}$, rapat arus $0.01 \mathrm{~A} / \mathrm{cm}^{2}$ pada dua jenis konduktor yang berbeda yaitu aluminium dan tembaga. Identifikasi warna berdasarkan RGB dan HEX untuk kondisi ini disajikan pada Tabel 3.

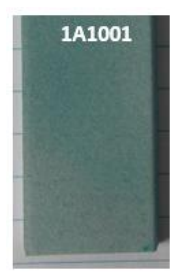

a)

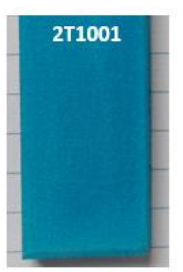

b)

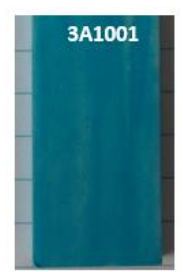

c)

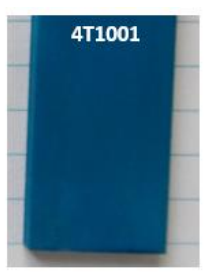

d)

Gambar 3. Benda kerja setelah proses pewarnaan yang diproses anodisasi 1 tahap dalam larutan 15 $\% \mathrm{H}_{2} \mathrm{SO}_{4}$ dan rapat arus $0,01 \mathrm{~A} / \mathrm{cm}^{2}$ dengan waktu dengan waktu 45 menit dan 90 menit menggunakan kawat konduktor tembaga dan aluminium untuk a) 1A1001, b) 2T1001, c) 3A1001, dan d) 4T1001.

Hasil pewarnaan permukaan aluminium setelah anodisasi pada rapat arus $0.01 \mathrm{~A} / \mathrm{cm}^{2}$ mengindikasikan bahwa pada durasi anodisasi 45 dan 90 menit (Gambar 3b dan 3d) penggunaan konduktor tembaga menghasilkan warna yang lebih merata daripada penggunaan konduktor aluminium (Gambar 3a dan 3c). Hal ini menyatakan bahwa kualitas pewarnaan pada aluminium oksida yang menggunakan konduktor tembaga lebih mendekati warna biru daripada penggunaan konduktor aluminium. Peningkatan durasi proses dari 45 menit menjadi 90 menit telah $\bigcirc$ mampu memperbaiki warna yang diperoleh pada permukaan aluminium. Hasil-hasil tersebut menerangkan bahwa konduktor jenis tembaga memerlukan waktu proses anodisasi yang lebih cepat daripada konduktor jenis aluminium. Jenis konduktor dalam proses anodisasi aluminium juga mempengaruhi kualitas warna permukaan benda kerja yaitu warna permukaan dan tingkat kerataan warna yang diperoleh. Kemungkinan perbedaan ini disebabkan konduktifitas logam konduktor. Logam tembaga mempunyai kemampuan hantaran listrik lebih baik daripada aluminium. Tembaga mempunyai nilai konduktifitas sebesar (7,00 $\hat{A} \pm 0,22)$, aluminium $(2,12 \hat{A} \pm 0,34)$ [15].

Tabel 3. Identitas warna lapisan aluminium oksida berdasarkan RGB dan HEX setelah proses anodisasi 1 tahap dan pewarnaan dalam larutan $15 \% \mathrm{H}_{2} \mathrm{SO}_{4}$ dengan rapat arus $0.01 \mathrm{~A}$, dengan variasi waktu dan menggunakan kawat konduktor aluminium dan tembaga.

\begin{tabular}{|ccccc|}
\hline \multirow{2}{*}{$\begin{array}{c}\text { Kode } \\
\text { Benda }\end{array}$} & \multirow{2}{*}{ Kawat } & \multirow{2}{*}{$\begin{array}{c}\text { Waktu } \\
\text { Konduktor }\end{array}$} & \multicolumn{2}{c|}{ Identitas Warna } \\
\cline { 4 - 5 } & & RGB & HEX \\
\hline 1A1001 & Aluminium & 45 & $86,109,105$ & $\# 566 \mathrm{~d} 69$ \\
\hline 2T1001 & Tembaga & 45 & $5,117,150$ & $\# 057596$ \\
\hline 3A1001 & Aluminium & 90 & $7,98,115$ & $\# 076273$ \\
\hline 4T1001 & Tembaga & 90 & $4,65,105$ & $\# 044169$ \\
\hline
\end{tabular}

\section{Pengaruh Jumlah Tahap terhadap Kualitas Warna}

Gambar 4 menunjukkan benda kerja yang telah diproses anodisasi 2 (dua) tahap dalam larutan $15 \% \mathrm{H}_{2} \mathrm{SO}_{4}$, rapat arus $0.01 \mathrm{~A} / \mathrm{cm}^{2}$ dan $0.02 \mathrm{~A} / \mathrm{cm}^{2}$ pada dua jenis konduktor yang berbeda yaitu aluminium dan tembaga. Pada konduktor aluminium, peningkatan rapat arus dari $0,01 \mathrm{~A} / \mathrm{cm}^{2} \mathrm{ke} 0,02 \mathrm{~A} / \mathrm{cm}^{2}$ (Gambar $4 \mathrm{a}$ dan $4 \mathrm{c}$ ) telah mampu memperbaiki kerataan pewarnaan pada permukaan aluminium, sedangkan pada konduktor tembaga (Gambar $4 \mathrm{~b}$ dan 4d) tidak terdapat perubahan distribusi pewarnaan. Hanya saja hasil pewarnaan permukaan aluminium pada konduktor tembaga memperlihatkan perubahan warna dari biru gelap menjadi biru terang.

Gambar 5 menunjukkan perbandingan antara permukaan aluminium yang telah melalui pewarnaan yang diproses dengan pembersihan secara elektrolisis dan tanpa pembersihan secara elektrolisis. Gambar 5 juga 
menunjukkan pengaruh rapat arus terhadap kualitas warna pada permukaan yang tanpa pembersihan secara elektrolisis dan permukaan dengan pembersihan elektrolisis.

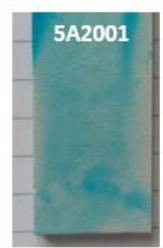

a)

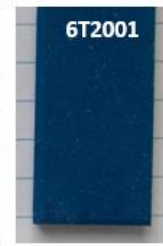

b)

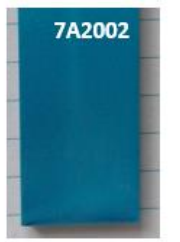

c)

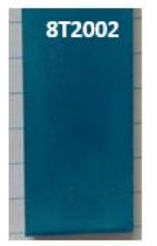

d)

Gambar 4. Benda kerja setelah proses pewarnaan yang diproses anodisasi 2 tahap dalam larutan 15 $\% \mathrm{H}_{2} \mathrm{SO}_{4}$, rapat arus $0,01 \mathrm{~A} / \mathrm{cm}^{2}$ dan $0,02 \mathrm{~A} / \mathrm{cm}^{2}$ dengan waktu 45 menit dan 90 menit menggunakan kawat konduktor tembaga dan aluminium untuk a) 5A2001, b) 6T2001, c) 7A2002, dan d) 8T2002.

Pada peningkatan rapat arus dari $0,01 \mathrm{~A} / \mathrm{cm}^{2}$ ke $0,02 \mathrm{~A} / \mathrm{cm}^{2}$ (Gambar 5a dan 5d), distribusi warna permukaan tidak mengalami perubahan dan tetap berwarna biru secara merata. Gambar 5b dan 5c menyatakan pengaruh pembersihan secara elektrolisis pada pewarnaan permukaan aluminium secara anodisasi pada total proses anodisasi yang sama yaitu 90 menit. Secara jelas dapat terlihat bahwa pembersihan secara elektrolisis (Gambar 5c) menghasilkan warna permukaan biru gelap dibandingkan permukaan aluminium yang tidak dibersihkan secara elektrolisis (Gambar 5b). Warna biru gelap pada permukaan aluminium ini menjelaskan bahwa pembentukan pori-pori terbentuk secara baik. Hal ini menyatakan bahwa pada konduktor tembaga proses pembersihan secara elektrolisis mampu meningkatkan pembentukan pori-pori permukaan aluminium.

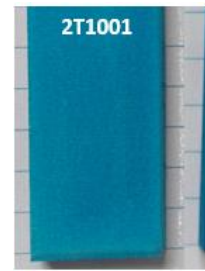

a)

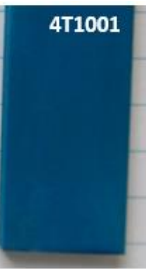

b)

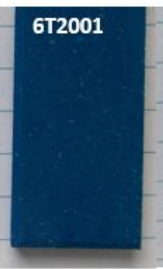

c)

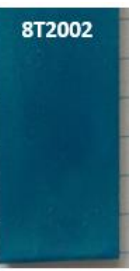

d)

Gambar 5. Benda kerja setelah proses pewarnaan yang aiproses anoaisasi 1 dan 2 tahap dalam larutan $15 \% \mathrm{H}_{2} \mathrm{SO}_{4}$, rapat arus $0,01 \mathrm{~A} / \mathrm{cm}^{2}$ dan $0,02 \mathrm{~A} / \mathrm{cm}^{2}$ menggunakan kawat konduktor tembaga tanpa pembersihan elektrolisis yaitu a) 2T1001, dan b) 4T1001, dan dengan proses pembersihan secara elektrolisis yaitu c) 6T2001, dan d) 8T2002.

\section{Pengaruh Jumlah Tahap Pembersihan dan Konduktor terhadap Konduktifitas Permukaan}

Pada Tabel 4 menunjukkan konduktifitas permukaan aluminium setelah proses anodisasi 1 dan 2 tahap pada konduktor tembaga dan aluminium. Pembacaan konduktifitas melalui ohm-meter dilakukan untuk mengetahui sifat permukaan aluminium oksida bersifat konduktor atau isolator. Pengujian dilakukan pada beberapa titik yang dilakukan secara acak dan dalam hal diperoleh hasil pembacaan yang bersifat konduktor, maka permukaan aluminium dinilai sebagai konduktor. Penilaian konduktifitas isolator dilakukan dalam hal pengujian menghasilkan nilai pembacaan yang bersifat isolator secara keseluruhan.

Hasil pengujian konduktifitas permukaan menggunakan ohm-meter menjelaskan bahwa permukaan oksida aluminium sebelum proses anodisasi adalah konduktor dan setelah proses anodisasi menghasilkan permukaan oksida aluminium yang bersifat tidak mampu menghantarkan arus (isolator) pada penggunaan konduktor tembaga, dan sebaliknya penggunaan aluminium sebagai konduktor menghasilkan sifat isolator. Peningkatan rapat arus dan proses pembersihan secara elektrolisis tidak mengubah sifat permukaan aluminum pada proses anodisasi yang bersifat konduktor atau isolator. Kondisi ini kemungkinan disebabkan ketebalan lapisan yang dihasilkan melalui konduktor aluminium lebih tipis daripada penggunaan konduktor tembaga, namun pori-pori tetap dapat terbentuk yang diindentifikasi melalui pelekatan warna tinta printer pada permukaan aluminium.

Tabel 4. Pengaruh rapat arus dan jenis konduktor terhadap sifat konduktifitas permukaan aluminium oksida.

\begin{tabular}{|ccc|}
\hline $\begin{array}{c}\text { Kode } \\
\text { Benda }\end{array}$ & $\begin{array}{c}\text { Rapat Arus } \\
\left(\mathbf{A} / \mathbf{c m}^{2}\right)\end{array}$ & $\begin{array}{c}\text { Konduktifitas } \\
\text { Permukaan }\end{array}$ \\
\hline 1A1001 & 0.01 & Konduktor \\
\hline $2 \mathrm{~T} 1001$ & 0.01 & Isolator \\
\hline
\end{tabular}




\begin{tabular}{|ccc|}
\hline 3A1001 & 0.01 & Konduktor \\
\hline 4T1001 & 0.01 & Isolator \\
\hline 7A2002 & 0.02 & Konduktor \\
\hline 8T2002 & 0.02 & Isolator \\
\hline
\end{tabular}

\section{Kesimpulan}

Proses pewarnaan secara anodisasi dapat diselenggarakan tanpa pembersihan secara elektrolisis dan melalui pembersihan secara elektrolisis, tinta printer yang tersedia secara komersial dapat digunakan untuk proses pewarnaan melalui jalur pembersihan secara elektrolisis, peningkatan rapat arus dari $0,01 \mathrm{~A} / \mathrm{cm}^{2}$ menjadi 0,02 $\mathrm{A} / \mathrm{cm}^{2}$ memberikan kontribusi pada peningkatan distribusi warna, proses pembersihan permukaan aluminium secara elektrolisis dapat meningkatkan pembentukan pori-pori permukaan aluminium dan konduktifitas benda kerja dipengaruhi oleh jenis konduktor yang digunakan; penggunaan tembaga menghasilkan lapisan oksida yang bersifat isolator, sedangkan penggunaan aluminium menghasilkan lapisan oksida yang bersifat konduktor. Secara lebih detil, perlu untuk melakukan identifikasi nilai-nilai konduktifitas dari jenis konduktor yang digunakan.

\section{Ucapan Terima Kasih}

Penelitian ini didanai oleh UPT P2M Politeknik Negeri Malang DIPA Nomor: SP DIPA042.01.2.401004/2019 Politeknik Negeri Malang dengan Surat Perjanjian Nomor 9881/PL2/KP/2019. Penulis menyampaikan terimakasih atas bantuan yang diberikan.

\section{Daftar Pustaka}

[1] G. B. Kauffman, 1990. "Chemical Demonstrations: A Handbook for Teachers of Chemistry, Volume 3 (Shakhashiri, Bassam Z.)," J. Chem. Educ., vol. 67, no. 6, p. A164.

[2] C. J. Donahue and J. A. Exline, 2014. "Anodizing and Coloring Aluminum Alloys," pp. 711-715.

[3] O. Jessensky, 1998. "Self-Organized Formation of Hexagonal Pore Structures in Anodic Alumina,"J. Electrochem. Soc., vol. 145, no. 11, p. 3735.

[4] D. Ma, S. Li, and C. Liang, 2009. "Electropolishing of high-purity aluminium in perchloric acid and ethanol solutions," Corros. Sci., vol. 51, no. 4, pp. 713-718.

[5] D. Veys-Renaux, N. Chahboun, and E. Rocca, 2016. "Anodizing of multiphase aluminium alloys in sulfuric acid: in-situ electrochemical behaviour and oxide properties," Electrochim. Acta, vol. 211, pp. 1056-1065.

[6] I. S. Molchan, T. V. Molchan, N. V. Gaponenko, P. Skeldon, and G. E. Thompson, 2010. "Impurity-driven defect generation in porous anodic alumina," Electrochem. commun., vol. 12, no. 5, pp. 693-696.

[7] W. J. Stẹpniowski and Z. Bojar, 2011. "Synthesis of anodic aluminum oxide (AAO) at relatively high temperatures. Study of the influence of anodization conditions on the alumina structural features," Surf. Coatings Technol., vol. 206, no. 2-3, pp. 265-272.

[8] H. Asoh, K. Nishio, M. Nakao, T. Tamamura, and H. Masuda, 2001. "Conditions for Fabrication of Ideally Ordered Anodic Porous Alumina Using Pretextured Al,” J. Electrochem. Soc., vol. 148, no. 4, p. B152.

[9] D. Nakajima, T. Kikuchi, S. Natsui, and R. O. Suzuki, 2018. Mirror-finished superhydrophobic aluminum surfaces modified by anodic alumina nanofibers and self-assembled monolayers, vol. 440. Elsevier B.V.

[10] H. P. Buwono, E. Yudiyanto, M. Muzaki, U. S. Amrullah, P. Udianto, and S. Hadi, 2019. "Tinta Printer Sebagai Pewarna Aluminium Oksida Yang Stabil Pada Proses Anodisasi Coloring," J. Elem., vol. 5, no. 2, p. 62 .

[11] H. Masuda and K. Fukuda, 1995. "Ordered Metal Nanohole Arrays Made by a Two-Step Replication of Honeycomb Structures of Anodic Alumina,” Science (80-. )., vol. 268, no. 5216, pp. 1466-1468.

[12] S. Yan et al., 2017. "Essential distinction between one-step anodization and two-step anodization of Ti," Mater. Res. Bull., vol. 95, pp. 444-450.

[13] X. Y. Han and W. Z. Shen, 2011. "Improved two-step anodization technique for ordered porous anodic aluminum membranes," J. Electroanal. Chem., vol. 655, no. 1, pp. 56-64.

[14] S. Ateş, E. Baran, and B. Yazıcı, 2018. "The nanoporous anodic alumina oxide formed by two-step anodization," Thin Solid Films, vol. 648, no. January, pp. 94-102.

[15] F. Nurdianah, 2015. "Analisa Sifat Konduktivitas Listrik Pada Sejumlah Logam Komersial,” Yogyakarta, Indonesia, 2015. [Online]. Available: http://etd.repository.ugm.ac.id/penelitian/detail/90397. 